(C) 2017 IEEE. Personal use of this material is permitted. Permission from IEEE must be obtained for all other uses, in any current or future media, including reprinting/republishing this material for advertising or promotional purposes, creating new collective works, for resale or redistribution to servers or lists, or reuse of any copyrighted component of this work in other works. 


\title{
Fast and Automated Verification of Multi-channel Full Time-Domain EMI measurement systems
}

\author{
Marco A. Azpúrua, José A. Oliva, Marc Pous, Ferran Silva \\ Grup de Compatibilitat Electromagnètica (GCEM), Departament d'Enginyeria Electrònica (DEE) \\ Universitat Politècnica de Catalunya (UPC) \\ Barcelona, Spain \\ email: marco.azpurua@upc.edu
}

\begin{abstract}
Recently, concern has been raised with regard to the adequacy of current verification practices carried out in electromagnetic compatibility (EMC) testing laboratories. Bridging the gap in the scope and reliability of the verifications performed in EMC laboratories requires faster and simpler verification methods to be performed prior testing. This paper presents a verification method for Full Time Domain Electromagnetic Interference measurement systems (Full TDEMI) that is intended to be quick and automated in order to become practical under the "just-before-test" approach. The method comprises a four stage process for assessing: sine-wave voltage accuracy, response to pulses, selectivity and input impedance. The verification method has been implemented and executed on an oscilloscope-based Full TDEMI achieving a reduction of time and effort involved while ensuring the compliance with CISPR 16-1-1 applicable requirements. Finally, this verification method improves the statistical significance because of the large number of points and conditions checked by the measurement automation software.
\end{abstract}

Keywords-electromagnetic compatibility; electromagnetic interference; just-before-test; quality management; standards.

\section{INTRODUCTION}

According to the definition given in the International Vocabulary of Metrology, verification is "the provision of objective evidence that a given item fulfills specified requirements" [1]. Incidentally, verifications shall be routinely yet rigorously carried out in accredited electromagnetic compatibility (EMC) testing laboratories. However, this might not be the general case, as explained below.

In a recent call from the European Metrology Programme for Innovation and Research (EMPIR), the ongoing Joint Research Project "RFMicrowave" (15RPT01) pointed out "...current knowledge between EMC and RF\&MW laboratories is very weak, which reduces awareness in measurements/calibrations and, therefore the overall quality of both EMC and RF\&MW measurements". One of the objectives of this very same project is to introduce a whole new set of verification methods suitable for EMC testing, that allow raising awareness of any problems just before starting tests [2].

The cornerstone of this "just-before-test" approach is that verification methods used in EMC testing must be reliable but also fast and automated for them to become compatible with the testing activities workload of certification laboratories. Depending on the particularities of certain EMC test, Vector Network Analyzer (VNA) and/or time-domain based verification methods are intended to address this "just-beforetest" approach.

Specifically, within the scope of the standards that define the radiofrequency emission requirements, verifications must be systematically performed in order to confirm the measuring receivers meets the specifications of CISPR 16-1-1 and the adequacy of the test setup [3]. This is a challenging task for a testing laboratory because most test receivers are not provided with any means for performing such verification.

In the vast majority of cases, testing laboratories only perform intermediate checks such as a manual corroboration of the amplitude/frequency accuracy of the test receiver or by means of the embedded self-test option found on most instruments. Moreover, those partial verifications are performed on a "from-time-to-time" basis and not "justbefore-test" mainly due to logistical constraints. Therefore, this current situation is against the best practices for assuring the quality of emissions testing.

In this regard, using a time-domain approach to the verification of electromagnetic interference (EMI) measuring receivers can reduce significantly the efforts required to perform instrument verification. Furthermore, (Full) TimeDomain EMI measurement systems [4]-[9] can benefit the most from time-domain verification methods because of the straightforward relationship between the expected outcome and the results of the verification in both time and frequency domains.

In this paper, a fast and automated verification method for multi-channel Full Time-Domain EMI (Full TDEMI) measurement systems is presented, intended to address the "just-before-test" approach. In that sense, first a summary of the key CISPR 16-1-1 requirement that must be verified in Full-TEDMI measurement systems is given (section II), then the implemented verification setup and algorithms are briefly described (section III) and the results of a verification of a Full TDEMI measurement system performed just before a conducted EMI testing will be presented as an example (section IV). 


\section{STANDARD REQUIREMENTS FOR FULL TDEMI MEASUREMENT SYSTEMS}

According to the standard definition measuring receiver, it is an "instrument such as a tunable voltmeter, an EMI receiver, a spectrum analyzer or an FFT-based measuring instrument, with or without preselection, that meets the relevant parts of this standard" [3]. In that sense, the proposed verification method shall provide objective evidence that a Full TDEMI measurement system fulfills the definition of measuring receiver concerning the compliance with requirements specified in the CISPR 16-1-1 standard.

Incidentally, the particularities of Full TDEMI measurement systems oblige to verify them differently in comparison with a frequency sweep or stepped scan receivers. Next, an overview of Full TDEMI measurement systems will be given in order to list a verifiable set of relevant requirements in terms of the CISPR 16-1-1 standard.

\section{A. Overview of Full TDEMI measurement systems}

In general terms, a Full-TDEMI measurement system is described by the block diagram shown in Fig. 1 [4], [7]. For the measurement of radiated EMI, a broadband antenna shall be used, while for the measurement of conducted EMI corresponds either a current clamp or a line impedance stabilization network (LISN). The measured signal could be amplified or filtered if this provides better sensitivity. In the analog-to-digital converter (ADC), the full spectrum signal is digitized and stored in the time-domain. Finally, the amplitude spectrum is computed via the spectral estimation techniques.

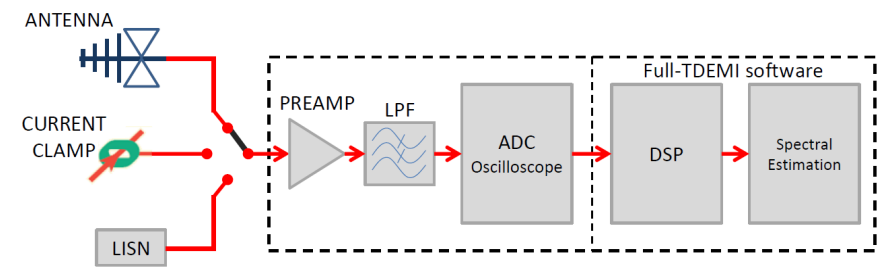

Fig. 1. The Full-TDEMI measurement system block diagram.

After deep memory acquisition, the software of the Full TDEMI measurement system performs signal processing tasks including windowing, resolution enhancing, resampling, spectral estimation (using the Short-Time Fourier Transform and the Welch's method) and the detector emulation. Those mathematical transformations are responsible for delivering the measurement results in accordance with CISPR 16-1-1 requirements [4].

\section{B. Applicable CISPR 16-1-1 requirements}

CISPR 16-1-1 (Annex K) gives two alternatives with regard to the demonstration of compliance of measuring receivers. The first possibility is using the manufacturer's calibration process for verifying compliance, but this is not feasible on a "just-before-test" approach primarily because reproducibility constrains. The alternative is using a verification process that includes at least the following parameters: voltage standing wave ratio (VSWR), sine wave voltage accuracy, response to pulses and selectivity.
The tables I and II summarize the standard requirements applicable to Full TDEMI measurement systems, in CISPR bands $A$ to $D$. Those items constitute the minimum set of requirements that shall be covered by the verification method.

TABLE I. APPLICABLE CISPR 16-1-1 REQUIREMENTS FOR FULL TDEMI MEASUREMENT SYSTEMS

\begin{tabular}{|c|c|c|c|}
\hline Parameter & Subclause & Requirements & Freq. ranges \\
\hline VSWR & $\begin{array}{r}4.2,5.2 \\
6.2,7.2\end{array}$ & $\begin{array}{c}2.0 \text { to } 1 \\
\text { ( } 0 \mathrm{~dB} \mathrm{RF} \text { attenuation })\end{array}$ & $9 \mathrm{kHz}-1 \mathrm{GHz}$ \\
\hline $\begin{array}{l}\text { Sine wave } \\
\text { voltage } \\
\text { accuracy }\end{array}$ & $\begin{array}{l}4.3,5.4 \\
6.4,7.4\end{array}$ & $\begin{array}{c}\text { Better than } \pm 2 \mathrm{~dB} \\
(50 \Omega \text { resistive source } \\
\text { impedance) }\end{array}$ & $9 \mathrm{kHz}-1 \mathrm{GHz}$ \\
\hline $\begin{array}{l}\text { Response } \\
\text { to pulses }^{\text {a }} \\
\text { (Absolute) }\end{array}$ & $\begin{array}{r}4.4,5.5 \\
6.5,7.5\end{array}$ & $\begin{array}{c}66 \mathrm{~dB} \mu \mathrm{V} \pm 1.5 \mathrm{~dB} \\
\text { (Flat spectrum within the } \\
\text { measured bandwidth) }\end{array}$ & $\begin{array}{c}\text { CISPR Bands A, } \\
\text { B, C and D }\end{array}$ \\
\hline $\begin{array}{l}\text { Response } \\
\text { to pulses }{ }^{\text {a }} \\
\text { (Relative) }\end{array}$ & $\begin{array}{l}4.4,5.5 \\
6.5,7.5\end{array}$ & Table II. & $\begin{array}{c}\text { CISPR Band A, } \\
\text { B, C and D }\end{array}$ \\
\hline \multirow{3}{*}{ Selectivity ${ }^{\mathrm{b}}$} & \multirow{3}{*}{$\begin{array}{l}4.5,5.6 \\
6.6,7.6\end{array}$} & $\begin{array}{c}90 \mathrm{~Hz} \leq B_{1,5} \leq 220 \mathrm{~Hz} \\
180 \mathrm{~Hz} \leq B_{6} \leq 220 \mathrm{~Hz} \\
180 \mathrm{~Hz} \leq B_{20} \leq 440 \mathrm{~Hz}\end{array}$ & CISPR Band A \\
\hline & & $\begin{array}{c}4 \mathrm{kHz} \leq B_{1,5} \leq 10 \mathrm{kHz} \\
8 \mathrm{kHz} \leq B_{6} \leq 10 \mathrm{kHz} \\
10 \mathrm{~Hz} \leq B_{20} \leq 20 \mathrm{kHz}\end{array}$ & CISPR Band B \\
\hline & & $\begin{array}{c}40 \mathrm{kHz} \leq B_{I, 5} \leq 140 \mathrm{kHz} \\
100 \mathrm{~Hz} \leq B_{6} \leq 140 \mathrm{~Hz} \\
100 \mathrm{~Hz} \leq B_{20} \leq 280 \mathrm{~Hz}\end{array}$ & $\begin{array}{l}\text { CISPR Bands } \\
\text { C and D }\end{array}$ \\
\hline
\end{tabular}

a. CISPR 16-1-1 Annexes B and C describe methods for determining the output characteristics of a pulse generator used in verifications and calibrations of the absolute and the relative pulse response.

b. $B_{x}$ means the reference bandwidth at the $x \mathrm{~dB}$ decay level.

TABLE II. REQUIREMENTS FOR THE RELATIVE PULSE RESPONSE OF THE STANDARD WEIGHTING DETECTORS

\begin{tabular}{|c|c|c|c|c|c|}
\hline Band & $\begin{array}{c}f_{\text {rep }} \\
(\mathrm{Hz})\end{array}$ & $\begin{array}{c}\mathrm{PK} / \mathrm{QP} \\
(\mathrm{dB})\end{array}$ & $\begin{array}{c}\mathrm{QP}^{\mathrm{Q}} \mathrm{QP}_{\text {(ref) }} \\
(\mathrm{dB})\end{array}$ & $\begin{array}{c}\mathrm{AV} / \mathrm{QP} \\
(\mathrm{dB})\end{array}$ & $\begin{array}{c}\text { RMS/QP } \\
(\mathrm{dB})\end{array}$ \\
\hline A & 10 & $10,1 \pm 1,5$ & $4,0 \pm 1,0$ & & $8,2 \pm 1,5$ \\
\hline A & 25 (ref) & $6,1 \pm 1,5$ & 0 & $12,4 \pm 1,5$ & $4,2 \pm 1,5$ \\
\hline A & 60 & $3,1 \pm 1,5$ & $-3,0 \pm 1,0$ & & \\
\hline A & 100 & $2,1 \pm 1,5$ & $-4,0 \pm 1,0$ & & $-1,8 \pm 1,5$ \\
\hline B & 10 & $16,6 \pm 1,5$ & $10,0 \pm 1,5$ & & $24,3 \pm 2,0$ \\
\hline B & 20 & $13,1 \pm 1,5$ & $6,5 \pm 1,0$ & & \\
\hline B & 100 (ref) & $6,6 \pm 1,5$ & 0 & $32,9 \pm 1,5$ & $14,3 \pm 1,5$ \\
\hline B & 500 & & & $22,9 \pm 1,5$ & \\
\hline B & 1000 & $2,1 \pm 1,5$ & $-4,5 \pm 1,0$ & $17,9 \pm 1,5$ & $4,3 \pm 1,5$ \\
\hline C,D & 10 & & $14,0 \pm 1,5$ & & \\
\hline C,D & 20 & & $9,0 \pm 1,0$ & & \\
\hline C,D & 100 (ref) & $12,0 \pm 1,5$ & 0 & & $20,1 \pm 1,5$ \\
\hline C,D & 1000 & & $-8,0 \pm 1,0$ & $38,5 \pm 1,5$ & $10,1 \pm 1,0$ \\
\hline C,D & 5000 & & & $26,3 \pm 1,5$ & \\
\hline
\end{tabular}

With regards to the requirements highlighted above some clarifications shall be made: a) VSWR requirements are only applicable to the $0 \mathrm{~dB}$ RF attenuation condition because Full TDEMI measurement systems have robust oscilloscope-type 
inputs and it is often unnecessary to use additional RF attenuation for protecting the instruments' input; b) Narrowband verifications at discrete suggested frequencies (the start, stop and centre frequencies) are replaced by broadband (full-spectrum) measurements; c) the pulse repetition frequencies used are above $10 \mathrm{~Hz}$ because this is the lowest mandatory pulse repetition frequency common to all CISPR frequency bands; d) for multi-channel Full TDEMI measurement system each channel shall be individually and independently verified.

\section{A JUST-BEFORE-TEST VERIFICATION METHOD}

As mentioned previously, the verification method described below is intended to address the requirements identified in section II following both the "just-before-test" and the "black-box" approaches. This means it comprises a procedure (automation algorithm) that verifies the instrument meets a specific response when a defined signal is applied to its input using a reduced set-up of instruments.

\section{A. The setup of the verification method}

The test setup is formed by a VNA and an Arbitrary Waveform Generator (AWG). In this particular case, the VNA R\&S ZVRE and the Pulse Function Arbitrary Generator Keysight 81160A (14-bit resolution) are employed.

On the one hand, the VNA is used for: a) measuring the VSWR and the impedance at the input of each channel of the Full TDEMI measurement system; b) measuring and correcting the cable attenuation. On the other hand, the AWG is used for synthesizing the reference tones and pulses required to verify the rest of the parameters. If the specific VNA/AWG used in the implementation has as many ports/outputs as inputs has the Full TDEMI measurement system, the procedure can be optimized by assigning an individual port/output for every measurement channel. This is significant because reduces the duration of the verification process through the simultaneous evaluation of all the channels of the Full TDEMI measurement system.

\section{B. Automation of the verification method}

The verification is automated by using a 5 stage routine embedded in the Full TDEMI measurement software application. Those stages are attenuation measurement, sine wave measurements (amplitude and frequency accuracy), pulse response measurements (absolute and relative), VSWR and impedance measurements and, finally, report generation. Those stages are executed in sequence, requiring a minimal level of interaction and surveillance from the technician, who is notified whenever it is required to change the connection between instruments if an error has occurred (i.e. communication errors), and when the verification process is completed. In the case it is possible to provide an individual signal source output for every measurement channel, end-user intervention is further reduced.

Cable attenuation measurements are performed in the first stage (Fig. 2). In that sense, VNA is configured to measure the complex $S_{21}$ using the maximum number of points (1601 in this case) in the frequency range required by the verification process. The results are acquired by the software application for calculating the corresponding attenuation correction factors of each channel. The process is repeated iteratively (for $i=1,2,3,4)$, one channel at the time.

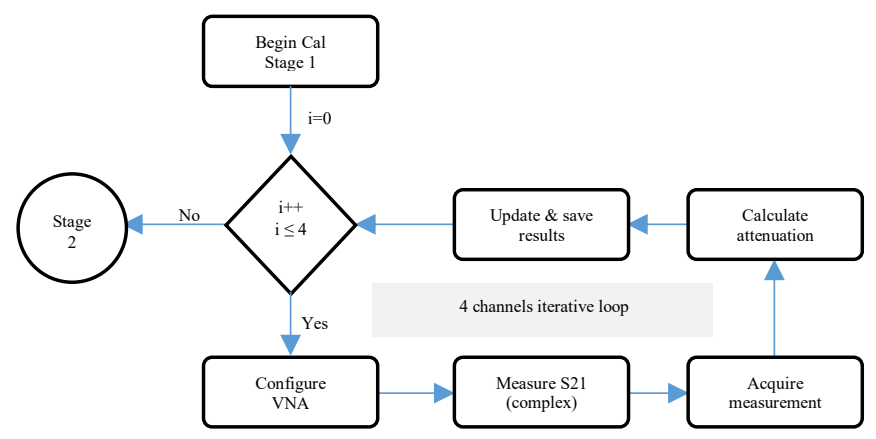

Fig. 2. Attenuation measurements flowchart (Stage 1).

Stage 2 is intended to verify the sine wave amplitude and frequency accuracy. For that reason, a sample of reference continuous wave RF tones that have certain, well-known, characteristics is generated. In this sample, the amplitude and frequency of the tones are selected using a hybrid randomsystematic approach without reposition and, in consequence, some restrictions are applied. Half the sample is formed by tones whose frequency are selected systematically to match exactly the frequency steps at which the spectral estimation is performed. The other half of the sample is tones that have a completely random frequency selected between the lower and upper measurement frequency of the CISPR band under verification. The amplitude of the tones is also randomly chosen within a configurable interval defined by a lower and upper bound around $66 \mathrm{~dB} \mu \mathrm{V}$. This hybrid sampling approach is used for collecting significant information about the measurement accuracy in the whole band under different sensitivity conditions (vertical scale). This data could be used to quantify the error contributions of frequency-overlapping and interpolation. Uniformly distributed pseudorandom number generators are used for defining the characteristics of the tones of the sample. The sample size, $N$, is defined as a percentage of the total number of measurement points.

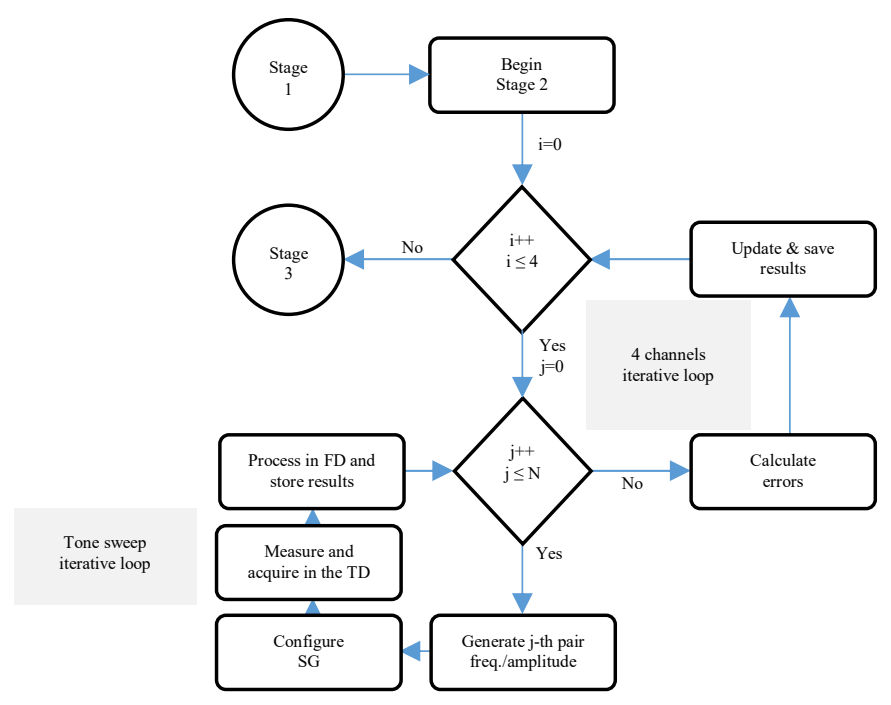

Fig. 3. Sine wave measurements flowchart (Stage 2) 
The process represented in the simplified flowchart of Fig. 3 shows the sine wave measurement stage is repeated iteratively for each tone within the selected sample and then for each channel (for $i=1,2,3,4$ ), one at the time.

Next, during the third stage, a specific pulsed signal is synthesized for having a flat frequency response $(66 \mathrm{~dB} \mu \mathrm{V}$ $\pm 1,5 \mathrm{~dB}$ ) while respecting the spectral density requirements that are summarized in Table III.

TABLE III. TEST PULSE CHARACTERISTICS FOR EMI TEST RECEIVERS [3]

\begin{tabular}{|c|c|c|c|}
\hline Band & Frequency & Impulse area & $f_{\text {rep }}$ (ref.) \\
\hline A & $9 \mathrm{kHz}$ to $150 \mathrm{kHz}$ & $13,5 \mu \mathrm{Vs}$ & $25 \mathrm{~Hz}$ \\
\hline B & $0,15 \mathrm{MHz}$ to $30 \mathrm{MHz}$ & $0,316 \mu \mathrm{Vs}$ & $100 \mathrm{~Hz}$ \\
\hline C & $30 \mathrm{MHz}$ to $300 \mathrm{MHz}$ & $0,044 \mu \mathrm{Vs}$ & $100 \mathrm{~Hz}$ \\
\hline D & $300 \mathrm{MHz}$ to $1000 \mathrm{MHz}$ & $0,044 \mu \mathrm{Vs}$ & $100 \mathrm{~Hz}$ \\
\hline
\end{tabular}

The pulse waveform shall be changed for each $j$-th CISPR bands under assessment because of the different requirements of the reference pulses. The pulse repetition frequency is set at the reference value for recording the absolute calibration. Then this process is looped for every repetition frequency in Table II in order to verify the relative response requirements of the weighing detectors. Once again, this process iterates until every combination of bands, channel, and pulse repetition frequency have been measured (Fig. 4).

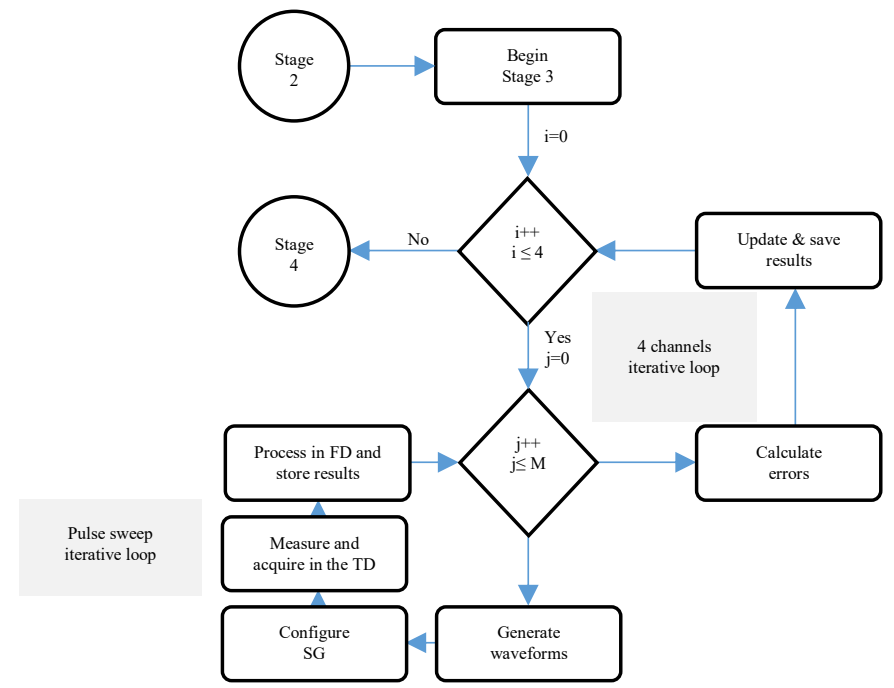

Fig. 4. Pulse response measurements flowchart (Stage 3).

In the fourth stage (Fig. 5), VNA is used to measure the complex voltage reflection coefficient at the input of each channel of the Full TDEMI measurement system. No RF attenuation is used.

Finally, in its last stage, the calibration algorithm generates the result plots and a report on an excel spreadsheet, including summary statistics as the Root Mean Squared Error (RMSE), the maximum error, the mean value, the standard deviation (STD) and the tolerances. This automatically generated summary report provides the user with concise information required to verify the Full TDEMI performance in terms of the standard requirements.

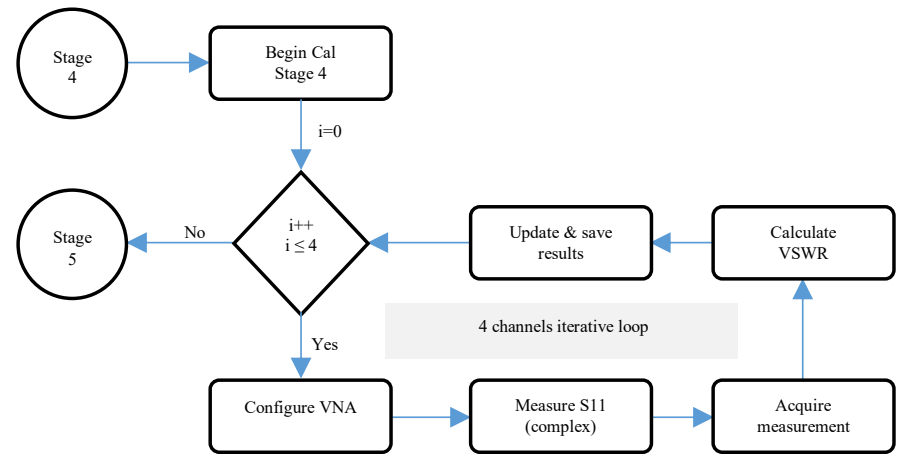

Fig. 5. VSWR measurements flowchart (Stage 4).

\section{VERIFICATION RESULTS}

In this section, the results of the verification of a specific Full TDEMI measurement system will be presented. It is the case of the Full TDEMI 4200 which relies on the USB oscilloscope "Picoscope 5444B" from Pico Technology ${ }^{\circledR}$. The Full TDEMI 4200 has 4 channels and $200 \mathrm{MHz}$ of nominal bandwidth. Thus, the verification will be performed in the CISPR bands $\mathrm{A}(9 \mathrm{kHz}-150 \mathrm{kHz})$ and $\mathrm{B}(150 \mathrm{kHz}-30$ $\mathrm{MHz}$.

Concerning the sine wave measurements, Fig. 6 shows the errors in amplitude (voltage) of the reference tones injected to the measuring apparatus for $N=200$. In both bands, and in every channel, the observed errors are below $1 \mathrm{~dB}$ in the worst case, as shown in Table IV.

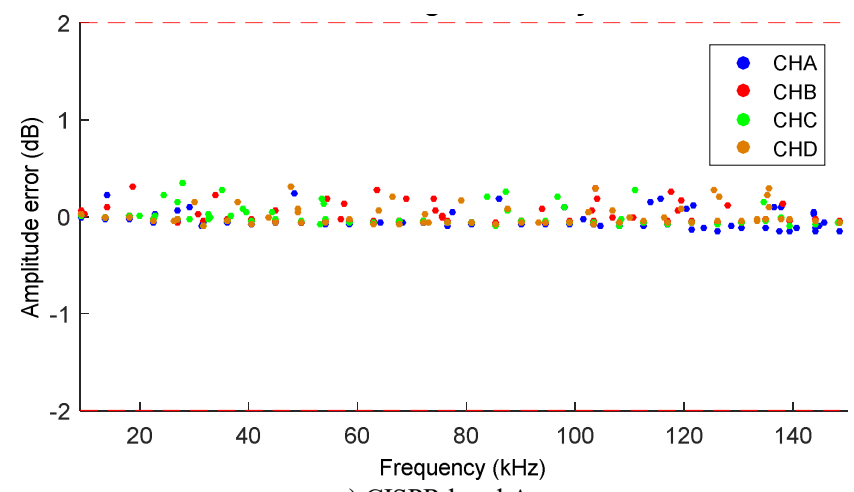

a) CISPR band $\mathrm{A}$

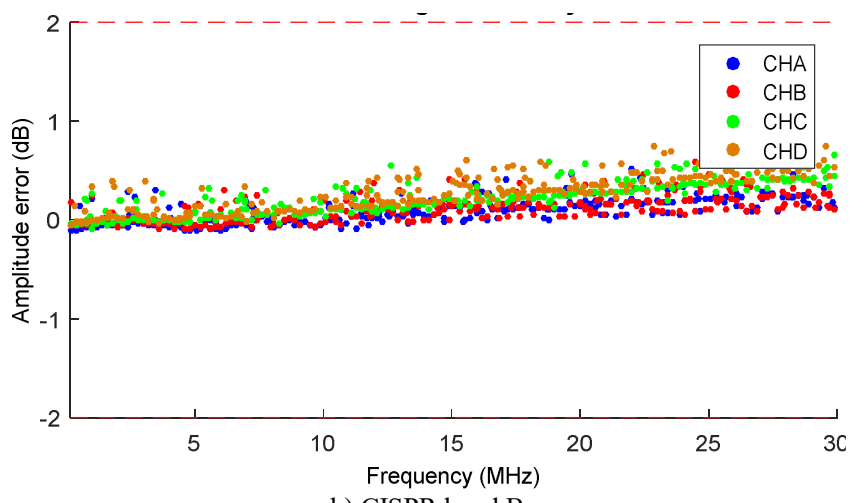

b) CISPR band $\mathrm{B}$

Fig. 6. Sine wave voltage accuracy verification results. 
TABLE IV. SUMMARY FROM SINE WAVE VOLTAGE ACCURACY VERIFICATION

\begin{tabular}{|c|c|c|c|c|}
\hline CH & Band & RMSE $[\mathrm{dB}]$ & Max $[\mathrm{dB}]$ & STD $[\mathrm{dB}]$ \\
\hline \multirow{2}{*}{$\mathrm{A}$} & $\mathrm{A}$ & 0.103 & 0.242 & 0.098 \\
\cline { 2 - 5 } & $\mathrm{B}$ & 0.168 & 0.599 & 0.138 \\
\hline \multirow{2}{*}{$\mathrm{B}$} & $\mathrm{A}$ & 0.108 & 0.319 & 0.105 \\
\cline { 2 - 5 } & $\mathrm{B}$ & 0.175 & 0.588 & 0.130 \\
\hline \multirow{2}{*}{$\mathrm{C}$} & $\mathrm{A}$ & 0.110 & 0.345 & 0.110 \\
\cline { 2 - 5 } & $\mathrm{B}$ & 0.283 & 0.685 & 0.167 \\
\hline \multirow{2}{*}{$\mathrm{D}$} & $\mathrm{A}$ & 0.109 & 0.307 & 0.108 \\
\cline { 2 - 5 } & $\mathrm{B}$ & 0.349 & 0.922 & 0.192 \\
\hline
\end{tabular}

Likewise, for the pulse response absolute measurements, Fig. 7 shows the results for each CISPR frequency band. The most relevant aspects to notice are the flatness of the frequency response and the ratios between peak/quasi-peak and quasi-peak average, which fulfill standard requirements. It is important to highlight this is a full-spectrum, multi-channel and multi-detector characterization of the pulse response. In both bands, for every channel and, all detectors the observed errors are below $1 \mathrm{~dB}$ in the worst case, as shown in Table V.

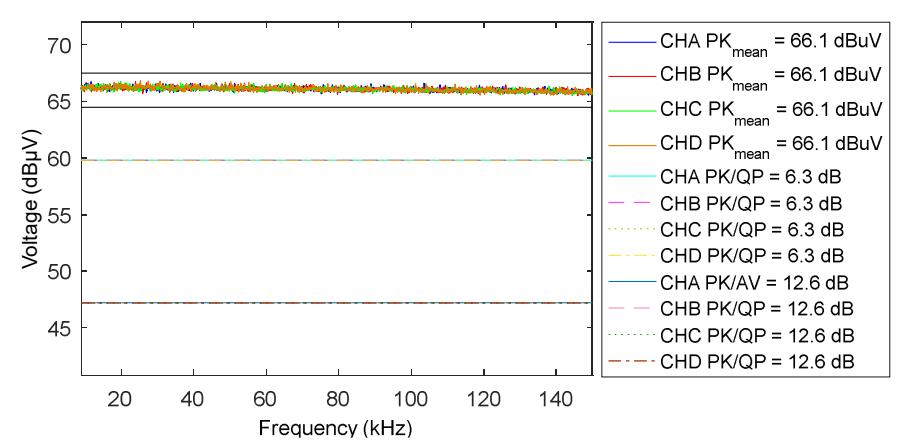

a) CISPR band $\mathrm{A}$

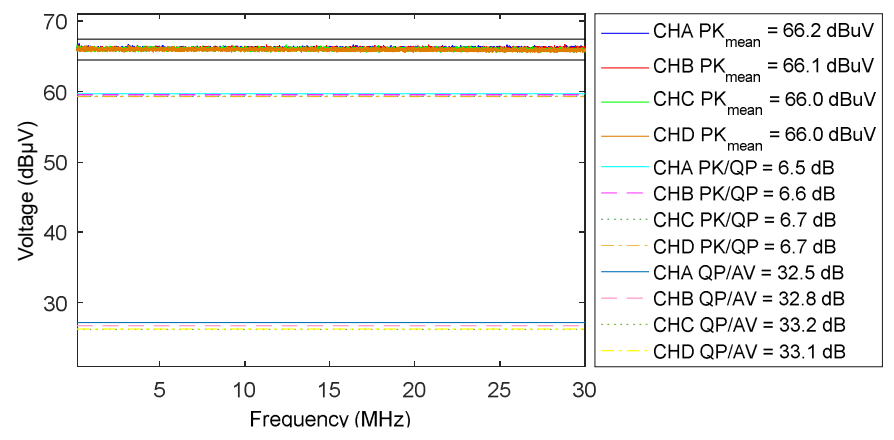

a) CISPR band B

Fig. 7. Response to pulses (absolute) verification results.

TABLE V. SUMMARY FROM THE ABSOLUTE PULSE RESPONSE VERIFICATION

\begin{tabular}{|c|c|c|c|c|c|}
\hline \multirow[b]{2}{*}{$\mathbf{C H}$} & \multirow[b]{2}{*}{ Band } & \multirow{2}{*}{$\begin{array}{c}\boldsymbol{f}_{\text {rep }} \\
{[\mathrm{Hz}]}\end{array}$} & PK & $\mathbf{Q P} / \mathbf{P K}$ & $\mathbf{A V} / \mathbf{Q P}$ \\
\hline & & & $\begin{array}{c}\text { Max error } \\
{[\mathrm{dB}]}\end{array}$ & $\begin{array}{c}\text { Max error } \\
{[\mathrm{dB}]}\end{array}$ & $\begin{array}{c}\text { Max error } \\
{[\mathrm{dB}]}\end{array}$ \\
\hline $\mathrm{A}$ & $\mathrm{A}$ & 25 & 0.716 & 0.168 & 0.189 \\
\hline $\mathrm{A}$ & $\mathrm{B}$ & 100 & 0.802 & -0.132 & -0.371 \\
\hline B & $\mathrm{A}$ & 25 & 0.764 & 0.173 & 0.195 \\
\hline B & $\mathrm{B}$ & 100 & 0.7 & -0.03 & -0.067 \\
\hline $\mathrm{C}$ & A & 25 & 0.75 & 0.173 & 0.196 \\
\hline $\mathrm{C}$ & $\mathrm{B}$ & 100 & 0.779 & 0.09 & 0.262 \\
\hline $\mathrm{D}$ & A & 25 & 0.837 & 0.182 & 0.207 \\
\hline $\mathrm{D}$ & $\mathrm{B}$ & 100 & 0.545 & 0.062 & 0.193 \\
\hline
\end{tabular}

With regards the relative pulse response verification, the results were satisfactory for all channels. Table VI shows only the results of the measurements performed on Channel A, because of space constraints. However, the differences in the relative pulse response observed among channels is negligible.

TABLE VI. RESULTS FROM THE RELATIVE PULSE RESPONSE VERIFICATION

\begin{tabular}{|c|c|c|c|c|c|}
\hline Band & $\begin{array}{l}\boldsymbol{f}_{\text {rep }} \\
{[\mathrm{Hz}]}\end{array}$ & $\begin{array}{c}\mathbf{P K / Q P} \\
{[\mathrm{dB}]}\end{array}$ & $\begin{array}{c}\mathbf{Q P / Q P} \mathbf{Q}_{\text {(ref) }} \\
{[\mathrm{dB}]}\end{array}$ & $\begin{array}{c}\mathbf{A V} / \mathbf{Q P} \\
{[\mathrm{dB}]}\end{array}$ & $\begin{array}{c}\text { RMS/QP } \\
{[\mathrm{dB}]}\end{array}$ \\
\hline A & 10 & 9.11 & 3.01 & & 7.55 \\
\hline A & 25 (ref) & 6.106 & 0 & 12.36 & 4.51 \\
\hline A & 60 & 3.16 & -2.93 & & \\
\hline A & 100 & 2.13 & -3.96 & & -1.38 \\
\hline B & 10 & 17.48 & 11.46 & & 25.13 \\
\hline B & 20 & 13.18 & 6.58 & & \\
\hline B & 100 (ref) & 6.66 & 0.06 & 33.09 & 14.91 \\
\hline B & 500 & & & 23.18 & \\
\hline B & 1000 & 2.13 & -4.47 & 17.85 & 4.83 \\
\hline
\end{tabular}

Finally, the Voltage Standing Wave Ratio (VSWR) is measured at the input of every channel of the PicoScope 5444B using a $50 \Omega$ termination in parallel to the high impedance provided by the instrument. VSWR measurement is displayed in Fig. 8. The measured VSWR remains below the 1.2 threshold even if the maximum allowed VSWR is 2 without an attenuator.

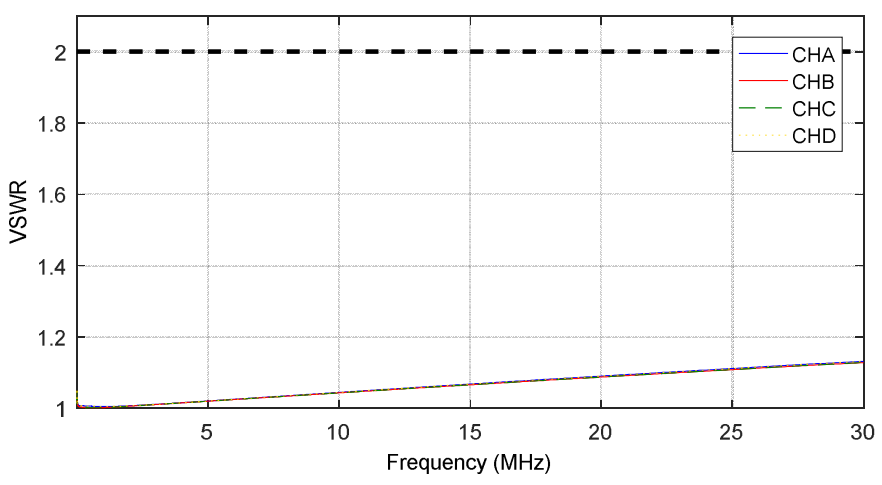

Fig. 8. VSWR verification results.

\section{CONCLUSIONS}

Throughout the examination of the results of the verification process, it was concluded this specific Full TDEMI measurement system performed in compliance with the CISPR 16-1-1 applicable requirements. The whole verification process (five stages) takes approximately 1 hour to be completed, using a standard desktop computer. This means, approximately $15 \mathrm{~min}$ per measurement channel, which is fast enough to be used under the "just-before-test" approach, whenever necessary. In fact, this activity could be executed during the warm-up time recommended for some measuring instruments, which means the verifications would not cause further delays in the typically busy schedule of an EMC testing laboratory. 
Moreover, this verification procedure could be used as the core of a calibration procedure of Full TDEMI measurement systems. In order to achieve this, further work shall be done in terms of the measurement uncertainty analysis and also with regards a well-defined measurement traceability chain.

\section{Acknowledgment}

This work was supported in part by the EURAMET 15RPT01 research project (the EMPIR is jointly funded by the EMPIR participating countries within EURAMET and the European Union) and by the Spanish "Ministerio de Economía y Competitividad," under project TEC2013-48414-C3-3-R.

\section{References}

[1] Joint Committee For Guides In Metrology (JCGM), "International vocabulary of metrology - Basic and general concepts and associated terms (VIM)," VIM3 Int. Vocab. Metrol., vol. 3, no. Vim, p. 104, 2012.

[2] "Publishable Summary for 15RPT01 RFMicrowave Development of RF and microwave metrology capability," 2015.
[3] IEC CISPR, 16-1-1 ed4.0: Specification for radio disturbance and immunity measuring apparatus and methods - Part 1-1: Radio disturbance and immunity measuring apparatus - Measuring apparatus. IEC, 2015.

[4] M. A. Azpúrua, M. Pous, S. Çakir, M. Çetintaş, and F. Silva, "Improving Time-Domain EMI measurements through Digital Signal Processing," Electromagn. Compat. Mag. IEEE, vol. 4, no. 2, pp. 66-74, 2015.

[5] M. A. Azpúrua, M. Pous, and F. Silva, "Decomposition of Electromagnetic Interferences in the Time-Domain," IEEE Trans. Electromagn. Compat., pp. 1-8, 2016.

[6] M. A. Azpurua, M. Pous, and F. Silva, On the Statistical Properties of the Peak Detection for Time-Domain EMI Measurements, vol. 57, no. 6 . IEEE, 2015, pp. 1374-1381.

[7] M. A. Azpúrua, M. Pous, and F. Silva, "A Measurement System for Radiated Transient Electromagnetic Interference Based on General Purpose Instruments," in Electromagnetic Compatibility (EMC EUROPE), International Symposium on, 2015.

[8] M. A. Azpúrua, M. Pous, and F. Silva, "On-board compact system for full time-domain electromagnetic interference measurements," 2016 ESA Workshop on Aerospace EMC (Aerospace EMC). pp. 1-4, 2016.

[9] M. Pous, M. A. Azpúrua, and F. Silva, Measurement and Evaluation Techniques to Estimate the Degradation Produced by the Radiated Transients Interference to the GSM System, vol. 57, no. 6. 2015, pp. 1382-1390. 